\title{
On the Public Affairs Openness in Chinese Local Government: A Case Study in Guangzhou
}

\author{
Ling Xu ${ }^{1}$, Qianfan $\mathrm{Li}^{2}$ \\ ${ }^{1}$ Guangzhou University, Guangzhou, China,xuling_1@126.com \\ ${ }^{2}$ Guangzhou University, Guangzhou, China,258559001@qq.com
}

\begin{abstract}
With the development of civilization, more and more citizens began to engage in public affairs, and it greatly pushed the government to pay much attention to building a transparency government. In light of this background, the public affairs openness becomes a hot topic not only on the theoretical research level but also in the government's practical sphere. In 2015, we held a cooperative research program with Haizhu District government in Guangzhou, which mainly focuses on the public affairs openness in Chinese local government. Then, we describe a case study on the Haizhu District government. Based on the first stage investigation, we found that the Haizhu District government's public affairs openness can be improved, or is just in the very beginning. Public affairs openness demands should be led by the citizen's desire instead of the upper-level government. Hence, the Haizhu District government should transform the whole public affairs openness model from the bureaucracy guiding style to the citizen guiding way.
\end{abstract}

KEYWORDS: citizens' satisfaction, local government, public affairs openness

\section{The background of the government affairs openness}

With the development of civilization, more and more scholars focus on the public affairs openness. Some scholars give a framework for information security governance and professional (Carcary et al. 2016), some scholars suggest exploring central themes in open government data and freedom of information research to realize the liberation of public data (Afful-Dadzie 2017), some scholars even discuss the latitude of information management in local government (Syväjärvi et al. 2017). The government affair has always been a crucial part of government work in the Guangdong Province. Theong Province. G mainly focusi government is active in exploring the reform of the government affair openness (thereafter called GAO) at various levels and the overall development to constantly push forward the development of the GAO work. Meanwhile, the government devotes to establish and improve the opening system and mechanism and develop a newly open pattern suitable to the development of the economy and society, and match to the demands of the populace. As early as November, 6th, 2011, G city of Guandong Province in which China's first local legislation on government affairs disclosure was promulgated, which is the first step in the development of government information, has taken the lead in the GAO of the whole country. In 2005 , the GAO regulations were further formulated by $\mathrm{G}$ city to cover all internet information system including all levels of government and departments. As a comparatively strong city, G is not only ahead in guaranteeing to uphold the legal system, but also quite effective on its practice. Meanwhile, a blue book on the Report of Transparency of Chinese Government (2014) by the Chinese Academy of Social Sciences Institute of Law shows the $\mathrm{G}$ city ranked the first in cities and provinces and respectively among 31 provinces and 49 comparatively big cities. Furthermore, the GAO work in the $\mathrm{H}$ district of $\mathrm{G}$ is regarded as a model. The open of the government information are realized by $100 \%$ electronization. The government in $\mathrm{H}$ has established 65 department websites, and 10 theme websites are included, and also has opened the column of the government affair that the government affair work goes smoothly. Meanwhile, the $\mathrm{H}$ district has opened the Wechat platform, on which 282 service issues can be completed.

According to the regulations, the public not only can get the actively opened government affair information, but also can apply to open the undisclosed information in accordance with the peoples' own needs on product, life and research work from the related department of the local government. The $\mathrm{H}$ district of $\mathrm{G}$ city demonstrated a good development trend. To better carry out the case analysis on the development of the GAO, the staff in this task group carried a practice investigation in the GAO department from November, 2011 to April, 2016. Questionnaires and interviews served the government and a task group explored new thinking and gave a direction for the further steps of the GAO work. 


\section{The GAO investigation in $\mathbf{H}$ district, $\mathbf{G}$ city}

\subsection{The GAO investigation to the government}

Some scholars have already finished some historical case study on the failure of an early episode in the open government data movement (Zhu 2017). Since the situation is changing rapidly, we have to think about the present. So we take a GAO investigation in $\mathrm{H}$ district of $\mathrm{G}$ city. The main task of this investigation was carried out as an intern researcher. During the study, one of the authors participated in the daily work of GAO in person and in the evaluation and data collection work. 44 questionnaires were given out to 27 branches and the subordinates in the whole district to ask the staffs in the government branches and streets, and then collected by the district government. In addition, the author randomly interviewed two departments on GAO work. The questionnaire for the government of $\mathrm{H}$ district included subjective questions to have the staff fill in the five aspects they believe should be disclosed and the ways to disclose them as well as whether the units have a clear transparency process to open and what is the specific way to disclose. In addition, two government units were selected randomly to have a further interview through the communication and coordination with the government.

\subsection{The investigation on GAO to the public}

Governmental officials and the public in $\mathrm{H}$ district were interviewed by snowball technique recruitment. The scopes of the survey include park, bus station and residential areas, etc. 300 people were interviewed. The survey derived basic information and investigated the public understanding of the government affairs, their evaluation and the aspects they participated in the GAO. There are one-sixth of the interviews aged 20 s-30s in this survey. Five-sixths of the sample had no idea about the GAO, two-thirds in this five-sixths think they will not take the initiative to apply the openness of the government affair. Among them, 149 are males and 151 are female, and 231 employed which account for $77 \%, 69 \%$ unemployed accounting for $23 \%$, with 111 local resident accounting for $37 \%$ and 189 resident coming from other cities which account for $63 \%$.

\section{The problems existing in the GAO: the contrast between the government in the GAO and the evaluation of the public}

There is a noticable contrast between the government and the populace. In the government, the work is carried out strictly in accordance with the relevant regulations imposed by the higher-level and rigorous in process and standardized in operation, and they have their own supervising and evaluating method. Through the further interview, the authors find that the government of $\mathrm{H}$ district got a full score in the evaluation. The government's work is perfect in its self-evaluation system. While the public, compared to the government's own high rank, is not so aware of it or does not care, and also, in comparing the two, there is a disconnect between the two parties in the GAO work, which is embodied in the following aspects:

\subsection{The inconsistence between the government and the public}

In recent years, The $\mathrm{H}$ district constantly pushed forward the government affair work according to the relevant provisions and regulations. It basically established a complete operation mode. The government places high importance to the GAO work. In the survey, the authors find that the evaluation score of GAO work of the government in $\mathrm{H}$ district reach the requirements as evaluated by the government. However, the public's concern is contrary to the government's self-evaluation. Based on 300 questionnaires, $83.7 \%$ of them are not aware of the GAO, and only one person expressed satisfaction and 9 gave an absolutely bad review. Satisfaction ranges from 1-5 with average grade 2.71 .

\subsection{The disconnection between the open content and the public's real need}

Although the government deems that all work is pushed forward in accordance with the relevant provisions and regulations, during the actual operation process, there existed a half-disclosed or pseudodisclosed information. Only some old information is disclosed, however, the vital and relevant vital information keeps closed. By processing and analyzing the questionnaires, the authors got the perception that the public is more concerned with food safety production (with the mean of 1.58), social security with the mean of 1.45 , government revenue and expenditure of 0.78 . The urban and rural planning progress is 
viewed at 0.71 mean standard, the policies and regulations at 0.66 mean, the government service guide and process at 0.65 mean, and the others at 0.71 mean. The public focuses on the food safety production, social security and government revenue and expenditure, which is the basic information related to the livelihood. However, most of the information disclosed by the government is about the organization structure, regulatory documents, financial budget and final accounts, work summary, plans, etc., which is not a good job in matching the content of the public's concern on the GAO.

\subsection{The GAO is not the channel that the public access for information}

According to the questionnaires, each sector and street of the $\mathrm{H}$ government use the following ways to access information, such as the portal website, the information disclosure catalogue and the government information disclosure column to disclose the information. While other channels - such as the government hotline and electronic display screens - are less used. The online publicity and information disclosure column are regarded as more commonly used methods by the government. However, due to the authority and convenience of the website, the channels the public accesses for the government information are mainly through information portals, TV stations and newspapers and magazines, which are more accessible to them. Compared with the government's more commonly used GAO modes such as portals, information disclosure, and government information disclosure, the GAO catalogue and columns are less commonly used by the public.

\subsection{The assessment indicator of the $G A O$ is not scientific}

$\mathrm{GAO}$ is one of the assessment indicators for the $\mathrm{H}$ government. The indicator system serves as a rough and simple assessment, which is based on the basic government affairs' opening work. The inspection is a simple and far way for work evaluation just based on the relative materials submitted by the audit department. There is no public evaluation to the GAO, only the government's from top to down. The public's satisfaction to the GAO is not assessed. Thus, it is impossible to access to the public opinion and call, and it is difficult to provide an effective push and supervision to the GAO.

\section{Causes analysis}

Now the model of the GAO work is influenced by the traditional governance concept and administration system. The model can be seen as a pyramid, in which the government makes the decision to express information to the public. This model is operated top-down under the lead of the government. There is no public participation in the confirmation of opening content, channel and assessment of information. The government is the only participant from the beginning to the end of the work. It can also be found that the government is not well-versed in the engagement and participation of the public and the integration of their opinion. The causes of this situation are presented in the following aspects:

\subsection{The restriction of the bureaucratic ideology}

Although democracy has been established in China, there is still a lot of backward political thinking in the political culture and in the existing political system. The traditional idea that people can be trained what to do but cannot be told why to do it is still existent. The public opinions is not paid much attention to. This kind of old thinking in some way hinders the development of the GAO. It also causes some of the personnel in the government organization to not have a real understanding to the significance of the GAO, so the GAO is regarded as the government's functions and powers, meanwhile it is regarded that the GAO will be affected the government's authority. Under the performance of the GAO, the government's statements and acts are exposed to the publics' supervision, but it lacks the power to guide the public to take part in. Meanwhile, the personnel holds some mistaken thoughts thinking the GAO's only task is to finish no matter what kind of significance it has. As time passed, the government is the only entity to push forward the GAO work. Some sectors just take the work as transactional, phased work and the change of the work function and the strategy of long-term development are not considered.

\subsection{The government operates top-down without the publics' opinion integrated}

During the government affair promoting process, the government considers their own interests more than the publics' needs and interests. An operation model from top-down is pushed by the government, which 
lacks of public participation. Derived from the interview and case survey, some government sectors actively take part in the promotion of the GAO, but seldomly stand at the side of the public to think and analyze whether the content, system, service, channel and assessment can be accepted by the public. The government seldomly encourages that the public takes the initiative to get the information, not to mention to give an education on "the right to know" to the public. The promotion of the work still stays at the "top down" promotion model. However, the GAO should be a two-way communication activity between the government and the public. The public's demands for information would better promote the development of the GAO, and the public's acquisition and attention to the information will foster the public's participation and discussion on the politics to promote the development of the legal system and the reformation of the democracy. Due to the lack of an effective feedback system, the further development of the GAO is severely restricted.

\subsection{The system of the GAO is not that sound}

The current GAO system needs to be further developed. To be seen as a whole, the states issued the provisions and regulations of the GAO at the beginning of the GAO. And the rules of the main aspects of GAO work are made from a macro scope, but there is still no all-agreed-system of standard requirements. The government is subjective and arbitrary in promoting it. Thus, there are not enough of legal and systematic guidelines which causes the government forming a model from top-down according to their management habits. The GAO should be an activity, in which the government is the subject and the public is the object. As the particular characteristics of GAO, the government should act in the leading role, but it does not mean that they can neglect the importance of the public. Without the participation of the public in it, the significance of this work will fade away. So the top-down operation model lacks of interaction, which causes the government to put a lot of energy in the work, but the public's concern still keeps low.

\section{Build a GAO model with governmental lead and the public's opinion being integrated}

\subsection{The concept of governmental leads and the public's opinion integrated}

The traditional bureaucratic ideology is an important cause to the problems in the GAO. To constitute the model of government leadership and the public's opinion integrated, the concept of the current GAO should be revised. The bureaucratic government should be changed and a new GAO established to increase the interaction between the government and the public to push the GAO work better integrated with the people's opinion. And two aspects are included in the concept.

- Build up a GAO management concept for the people

In order to establish a GAO model with the government leadership and the public opinion integrated and to change the current bureaucratic management concept to cater to the public, a client-oriented concept should be introduced. The client here is an analogy to the relationship between the government and the people. It is the people who accept the public products and service. In public management, whether they are satisfied with the products decides the quality and future of the government. The meaning of the client's orientation refers to that the team and members stand at the client's side. This concept regards the client as an important asset and a lost client will mean to loose a main asset. The government should carry out a resource management and seek the satisfaction of the public as the final target. The focus of the government's work is to provide the common products and services, which the public anticipated. The client-oriented GAO concept and model is a responsible management method for the public and it is the public-oriented government. The change of the traditional administrative pattern of the bureaucratic government plays a role in meeting the public's demands, improve the work efficiency, make the relationship between the government and the people more harmonious and enhance the service quality. The government should set up a GAO management concept for the public, constantly increase its work quality during the management process and implement the service thoughts upholding citizens as clients. All these means will make the public satisfied and improve the communication between the two, perfect the communication channel, and improve the initiative of the public's participation in government affairs. The government should do their work better under the supervision of the public. 


\section{- Set up a GAO idea with the interaction between the government and the public}

The government's leading role in the GAO work cannot be shaked, however, the participation of the public also cannot be ignored. According to the concept of the government lead and public's opinion integrated, it is required that the government should be responsible for the service provided to the public in the process of GAO to avoid power abuse. Only with a good interaction between the government and the public, can the demands of the public be really understood, the deficiency of the government's work be known and the improving direction of the GMO be clear. Being open and transparent is a good interaction between the government and the public and also it is the public's right to know and a guarantee to the public to take part in the politics to standardize the government's behavior, enhance the efficiency and prevent corruption. To protect the mass at a maximum degree will help safeguard the democratic status of the citizens, and foster them to take part in and supervise and it will also help to enhance the public relationship between the government and the populace.

\subsection{The operation principle of the model in the government lead and public opinions integrated}

According to the requirements on building up a service government and the guidelines on client-oriented public management concept, the government comes up with the model of government lead and public's opinions integrated based on the current model of GAO. This model is not a negation, but a revision to the current GAO. Based on the affirmation to the government's leading role in the GAO, the government uses the government lead as a main line to carry out the GAO, and the public's integration as the subordinated aid. Although there is a lack of the public's participation and concern in the GAO, it cannot deny the leading role of the government. The government is the main part in GAO, and the GAO belongs to one category of properties of the government's public service.

Due to the government's natural monopoly to provide public services and products, and also the GAO has the same special characteristics as other public service products, the government needs to play a leading role on it. It needs the government's work to invest human labor, energy, and to build relevant procedure and legal systems, thus only the government has the right to do the above work. The government should take the initiative to guide the public to take part in the government affairs to improve the operating model and enhance the publicity. The government should supply a variety of ways as much as possible to make more citizens participate in the GAO. For the sake of making the citizens join in the GAO to improve the work efficienc; the government takes the lead to build a suitable model of GAO to safeguard the work to be open, stable and sustainable. Thus, the government's status should be affirmed in the government affairs and based on this explore how to meet the public's demands and be willing to integrate them with the government affairs.

According to the survey, many problems in GAO are caused by the lack of full communication between the government and the public. There is no public participation on the content, channel and supervision of the work. The government should pay attention to the public for the sake of improving or solving some relevant questions, should encourage and guide the public to participate in the GAO work and should attach importance to the public's practical and needed information to meet their multi-faceted demands. Then, the problems in GAO will be avoided or solved. However, the GAO is not a one-man show, the government is not the man who knows it all. There is an interaction effect between the government affairs and the public opinion. So the government should integrate the public's opinion as much as possible in the leadership of the government.

\subsection{The process of government lead with the public's opinions integrated}

According to our research, there still exist some problems in the current GAO model. To solve these problems, an important direction is to improve the role of the public based on the current work model. And according to the survey, the public does not know much about the GAO. The open content disjointed with the public's practical needs and the open channels are not the ones people uses. The evaluation indicator reveals deficiencies. A crucial cause for these problems above is the process of the GAO. The essence of the GAO is to serve the mass and safeguard their right to know. So the process of the GAO should take the public as the starting point, and integrate their opinion in each single step and set up the target according to the public's opinion. After the fix of the target, the open policy or action plan of the target should not be carried out without examining the public's opinion. After the executing of the task, the evaluation work 
cannot only been done inside of the government, but should integrate the public's opinion and evaluation. Only by this way, can the whole work be evaluated comprehensively. The government leads and public's opinion integrated model takes the public's view into each step of the process. It is not a denial to the traditional model but an improvement and revise based on the traditional model.

\subsection{The system matched to the Government lead and public's opinions integrated}

To build a government lead with the public's opinion integrated, it needs a system to safeguard the operation of the model other than revise and reproduce. Only with a standard system, an effective survey system to the public's opinion, and perfect evaluation system to support, can the government leads and public's integrated be implemented.

\section{- The legal guarantee of the government leads, the public's opinions integrated}

The legal norm is the basis and safeguards to guide the realization of government leadership with public's opinions integrated. Based on the current legal system of GAO, the concept, current process and detail operating model of the GAO are fixed in the form of rules and regulations. Only in this way, can rules and regulations be followed by the government leadership with public's opinion integrated during the process to safeguard the standardization and authority of the model. First, the model should be determined and confirmed by the laws and regulations. Second, the detailed open content and scope should be stipulated in systematic rules carried out to integrate the public's view during the open process. Finally, a specific provision shall be made to evaluate the public's opinion on GAO. The government should perfect the evaluation system and integrate the public's participation and opinion as one of the evaluation indicators. Only by this, can the evaluation work be carried out to the GAO to foster its progress.

\section{- Establish a regular and irregular public's opinion survey system}

Given the difference of the government lead and public's opinion integrated it is necessary to conduct regular and irregular public's opinion survey system into the current GAO system. There is no doubt in the importance of the public's participation in government affairs. But the initiative of the public to join in the GAO is not high. A clear knowledge about the public's demands and listening to the public's voice are needed if the government wants to take the public's satisfaction as the target. The government can further improve the system and set up an effective public's opinion survey system from the aspects of enriching the participating ways, expanding the interaction channel, etc. Establishing an effective survey system can help the government have better understanding of the people's demands and listening to the people's voice, then obtain the people's respect. The government should carry out a regular and irregular survey which an active participation and cooperation is indispensible.

\section{- Build a double dimensional assess system between the government and the people}

The evaluation system of the government leads with the public's opinion integrated should be a system participated by the government and the public. At the time the inner supervising system is affirmed and perfected, the outer supervision should be pay further attention to. First, enhance the inner self-evaluation system. It is extremely necessary to enhance and perfect the evaluation system which is the safeguard to the effective and sustainable operation of the GAO.

The government should perfect the evaluation system by enhancing the practice effect by using a standard form, but also investigate and punish mistakes, omissions and the act of substandard according to relevant provisions of standards. Inner supervision will safeguard the seriousness of the model program. Second, the government should pay attention to the outer evaluation, which includes the public as the main actor. The outer evaluation and supervision are mainly divided into two ways. One are other power institutions outside the administration including legislative and judicial supervision. Another is the social supervision, in which the main part is the public.

The former open evaluation system usually only focused on the relevant evaluating institutions and their sectors, and neglected the social supervision. However, due to the difference among the sectors and the asymmetry of the information, the outer evaluation of the power can only evaluate the results by social supervision, which should be enhanced, particular the public's opinion should be sought as the focus of future concern. 


\section{References}

Afful-Dadzie, E., and A. Afful-Dadzie. 2017. "Liberation of Public Data: Exploring Central Themes in Open Government Data and Freedom of Information Research.” International Journal of Information Management 37 (6): 664-672.

Carcary, M., K. Renaud, S. McLaughlin, and C. O'Brien. 2016. “A Framework for Information Security Governance and Management." IT Professional 18 (2): 22-30.

Syväjärvi, A., J. Leinonen, V. Kivivirta, and M. Kesti. 2017. "The Latitude of Information Management in Local Government: Views of Local Government Managers." International Journal of Electronic Government Research 13 (1): 69-85.

Zhu, Xiaohua. 2017. "The Failure of an Early Episode in the Open Government Data Movement: A Historical Casestudy.” Government Information Quarterly 34(2): 256-269. 